\author{
S. Urbanowski ${ }^{* 1}$, P. Luczkiewicz ${ }^{2}$, S. Grymek ${ }^{1}$ \\ ${ }^{1}$ Gdansk University of Technology, Faculty of Mechanical Engineering, Department of \\ Machine Design and Motor Vehicles, Narutowicza 11/12, 80-233 Gdańsk, Poland \\ ${ }_{2} 2^{\text {nd }}$ Department of Orthopaedics \& Kinetic Organ Traumatology, Medical University of \\ Gdansk, M. Smoluchowskiego 17, 80-214 Gdansk, Poland \\ *sebastian.urbanowski@gmail.com
}

\title{
ANALYSIS OF BONE WEDGE DIMENSIONS SELECTION METHODS IN HIGH TIBIAL OSTEOTOMY
}

\begin{abstract}
The article presents the analysis of methods for selecting dimensions of bone wedge for high tibial osteotomy. The existing methods are described along with the procedure. In the following paragraphs, deficiencies in the selection of bone wedge dimensions and global trends in this field have been demonstrated. Based on the numerical analysis, the problem appearing in the wrong choice of bone wedge dimensions was illustrated.
\end{abstract}

Keywords: implantation, bone deformation, Young's modulus

\section{INTRODUCTION}

The treatment of popliteal osteotomy is a common method of preventing the consequences of degenerative changes occurring in the knee joint. Degeneration of articular surfaces occurs irrespective of the place of residence. The main pathogenic factors are: age, female sex, joint infection, increased body weight, previous injuries, occurrence in the family, neuromuscular disorders and metabolic and rheumatic diseases [1]. The disease occurs with the same frequency in male and female patients aged from 45 to 55. In old age it comes to intensify the occurrence in female [2]. As a result of these changes, there are symptoms, such as pain or difficulty moving, the occurrence of which is intensifying. It leads to a deterioration of the standard of living.

Popliteal osteotomy is an invasive procedure, leading to a significant improvement in joint function. This effect is obtained by correcting the axes of forces running in the joint. This leads to a reduction in the abnormal loading of the knee joint, the cessation of disease processes and stimulates the reconstruction of articular cartilage [3].

There are many methods for determining the dimensions of the bone wedge, but they don't take into account the impact of different Young's modulus of bone and implant. Theoretically the deformation of bone is approximately ten times higher than steel implant deformation under the same load. This can be the cause of complications after HTO. 
In article various methods for determining the dimensions of the bone wedge and the types of complications after intervention were described. After the description of the methods, the focus was placed on the effect of the various Young's modulus of bones and steel on the change in the correction angle compared to the intentional value. After short theoretical introduction FEM analysis was carried out for proximal end of tibia in static load condition in two different cases. In the first case the material of model was only bone, but second model included a ten degrees wedge made of steel. Result of correction was measured as a difference of deformation of tibial condyles. Finally, the results were presented and the need to extend the research with dynamic load states was indicated. The bone with ten times less Young's modulus should theoretically deform ten times more than steel wedge. This was not observed. Side with steel wedge was deformed by $4.117 \cdot 10^{-3} \mathrm{~mm}$, while lateral bone side was deformed by $4.94 \cdot 10^{-3} \mathrm{~mm}$. The difference in deformation is only $0.823 \cdot 10^{-3} \mathrm{~mm}$ but is two times higher than in uniform bone. Also increased stresses were observed on the border of different material.

Proper selection of the biomaterial of the implant is important for long term implantation. Human tissue environment does not accept any type of materials. To minimize an immunological performance of human body, implants material should be chosen correctly [4]. Typical material for locking plate is 316L stainless steel [5]. Currently the gold standard of implant used in HTO procedure is fixation plate from pure titanium [6, 7]. Another kind of HTO implants material is polyetheretherketone (PEEK), carbon short-fibre-reinforced (CSFR) PEEK and carbon long-fibre-reinforced (CLFR) PEEK [6, 8]. Modern methods of implant preparation use additive manufacturing like SLM (Selective Laser Melting). To create an implant with similar stiffness to bone, the implant should be modelled as lattice [9].
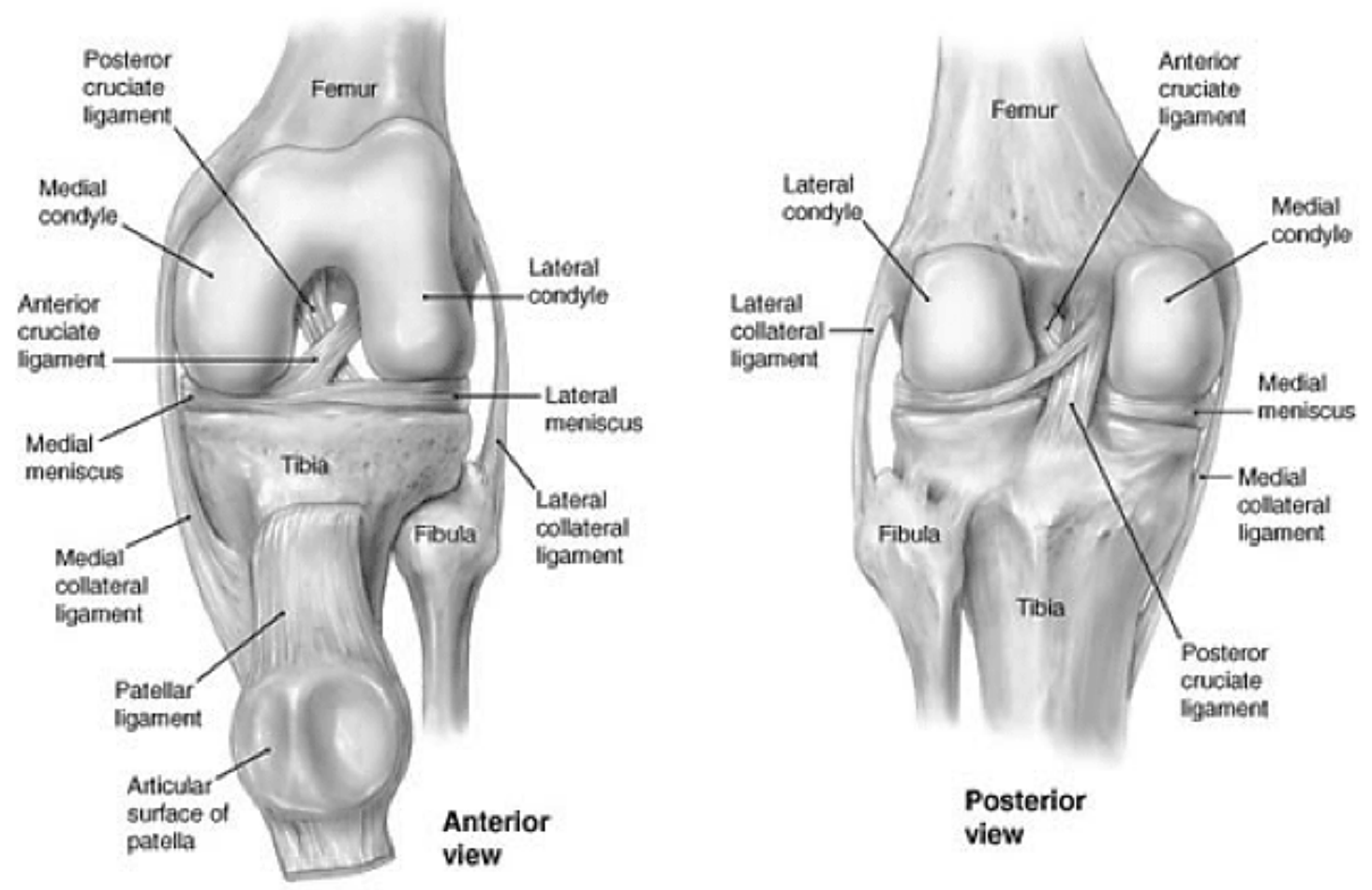

Fig. 1. Anatomy of a knee joint [10] 
A knee joint is the largest synovial joint in the human body [11]. It connects the femur bone with the tibia bone. Another bone which forms the joint is the patella. Cooperative joint surfaces of the femur and tibia are characterised by a significant disproportion in size and a large mismatch of shape. As a result, the size of the contact surface of both bones is small. In combination with the fact that the knee joint moves almost all the weight of a human body, it can be said that it is one from the most-loaded joints. The meniscus, lateral and medial present in the joint deepen joint surfaces improving the cooperation conditions by enlarging the contact area. The anatomical structures that provide stabilisation of a knee joint are ligaments and tendons. Two main groups of ligaments should be distinguished: internal and external ones. Among the external ligaments, ligaments attached to the patella, which stabilise the joint capsule from the front should be distinguished. Another group belonging to external ligaments are side ligaments - strengthening the joint from the lateral and medial side. Internal ligaments consist of cruciate ligaments and lateral ligaments of the knee. A knee joint is surrounded by a joint capsule.

The movements that can be distinguished in the knee joint are [12]:

- bending $\left(140^{\circ}\right)$,

- straightening $\left(180^{\circ}\right)$,

- rotation - outside $\left(30-40^{\circ}\right)$, inwards $\left(5-10^{\circ}\right)$.

The following considerations focus on the treatment of wedge osteotomy of the tibial high end (HTO - high tibial osteotomy).
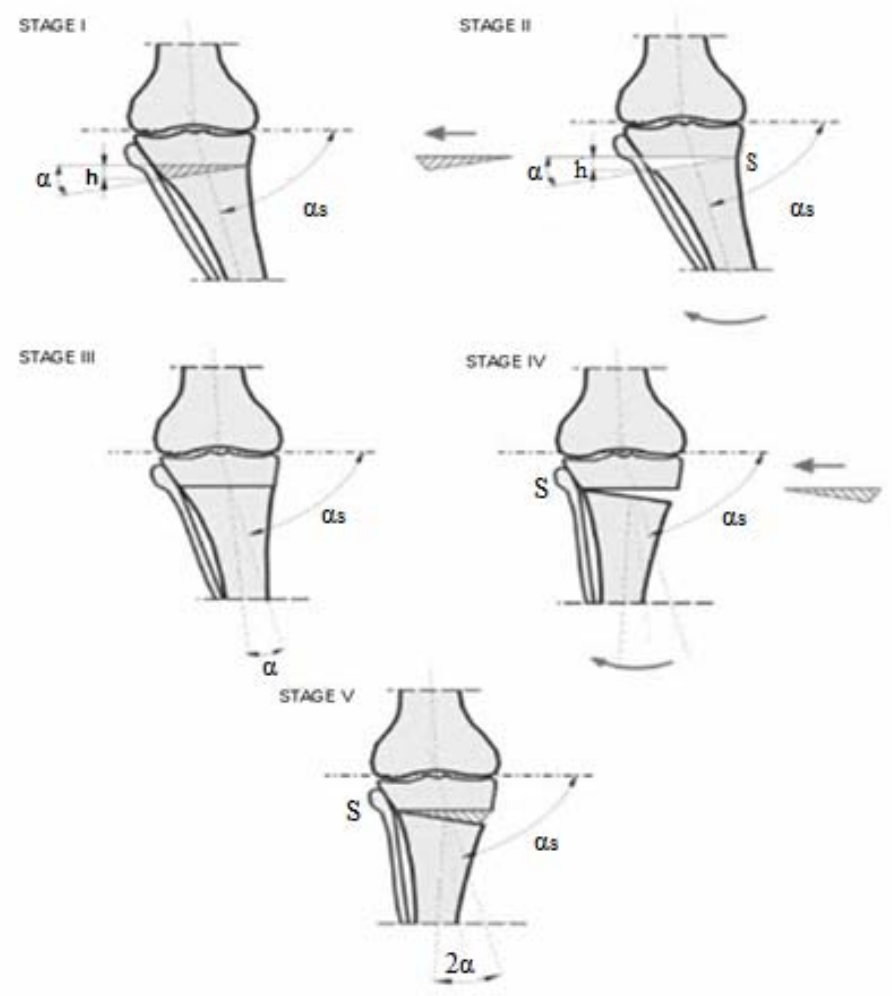

Fig. 2. Subsequent stages of high tibial bone osteotomy [13]

Two basic types of tibial osteotomy should be distinguished. The first is a closing osteotomy, while the other is the opening osteotomy. In order to properly perform the correction, the appropriate displacement of the knee joint load axis should be determined. 
Next, the required correction angle and bone wedge height should be calculated. One of the methods of determining the correction angle in the closing osteotomy is the Lobenhoffer method [14]. Determination of the correction angle should be started by drawing a mechanical axis of the knee joint. It is carried out in the frontal plane, between the centre of the femoral head and the centre of the distal end of the tibia bone. In figure $3 \mathrm{a}$ it is represented by a long grey line (1). Next, the line of the desired course of knee joint load is plotted. Fujisawa [15, 16] developed recommendations that say it should be drawn from the centre of the femoral head and pass through a point located on the articular surface of the proximal end of the tibia. This characteristic point is located at $62.5 \%$ of the width of the tibia. This line is shown in figure $3 \mathrm{a}$ as long black line (2). At this point, the location of the wedge's peak is determined. In the closing osteotomy, it is located on the medial surface of the proximal tibial bone. Next, a line should be drawn from the wedge's peak point leading to the centre of the ankle; it is presented as a short grey line (3) in figure 3a.Then the line that runs from the wedge's peak point leading to the intersection of the ankle axis with the line defining the desired mechanical axis of the joint after correction should be drawn. It is depicted as a short black line (4) in figure $3 \mathrm{a}$.
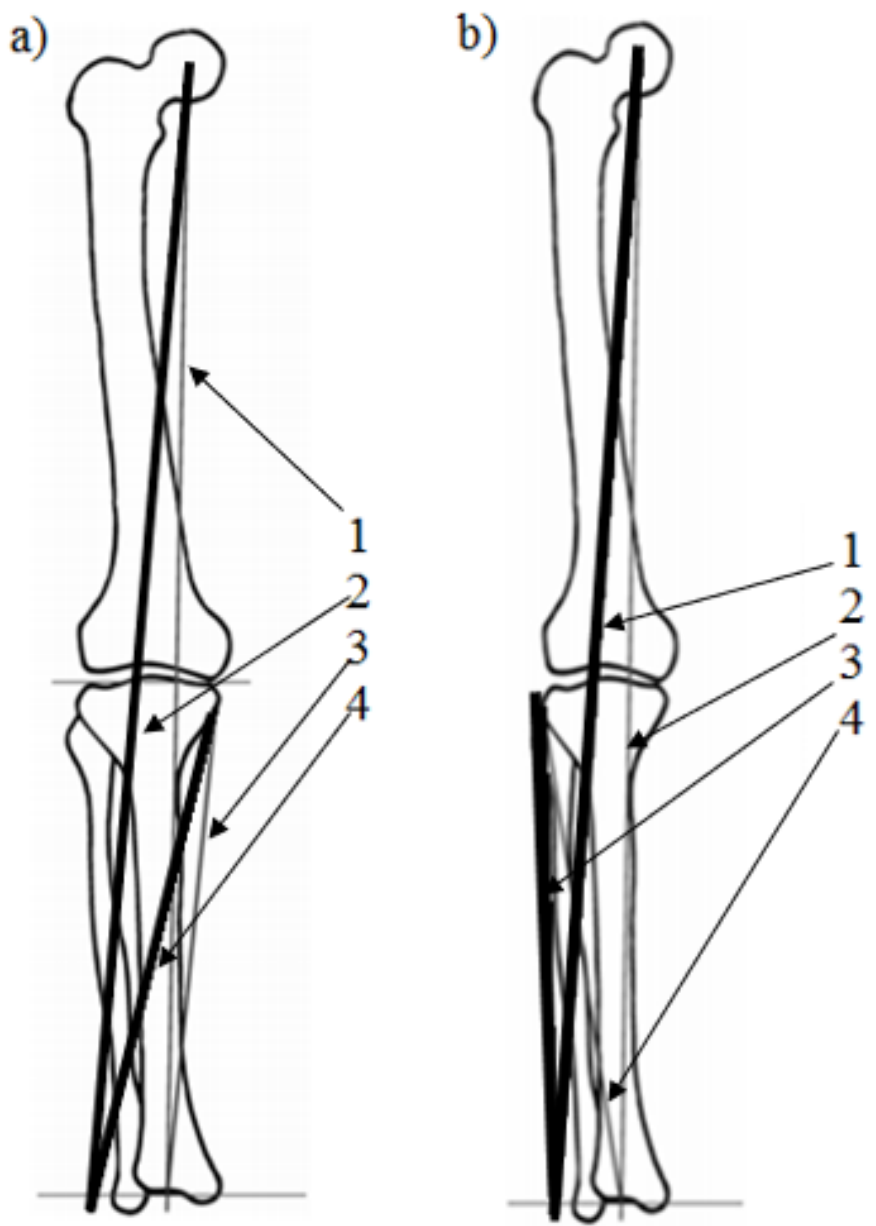

Fig. 3. a) Plotting the correction angle in the closing osteotomy, b) Deletion for opening osteotomy [13]

The angle determined by the lines originating from the wedge's peak is equal to the value of the correction angle. The last step is to determine the height of the bone wedge. It involves transferring the obtained angle to the place where the osteotomy is planned and measuring the height of the wedge. Next, the proportions resulting from the X-ray scaling should be taken 
into account. Another method of determining the size of the wedge base is to calculate its value from the following formula [17]:

$$
H=0.02 \cdot S \cdot K
$$

where: $\mathrm{H}$ - the dimension of the bone wedge base, $\mathrm{S}$ - the width of the tibia bone in the place of planned surgery and $\mathrm{K}$ - desired correction angle in degrees.

In the literature, one can find the method of determining the height of the bone wedge $(\mathrm{H})$ according to the rule which says that one millimetre of the height of the bone wedge base corresponds approximately to one degree of correction required [18].

When plotting the correction angle in the dissection osteotomy with medial access, another location should be considered for the position of the tip of the bone wedge. Lines should be run from the medial surface of the proximal tibial bone from the fibula side to the intersection of the mechanical axis line and the line passing through $62.5 \%$ of the width of the tibia with the axis of the ankle joint. An example of a deletion for the opening osteotomy is shown in figure $3 \mathrm{~b}$. As can be seen in figure $3 \mathrm{~b}$ the correction angle is located between two short lines, black (3) one and grey (4) one which come out of tip of the wedge. Long black line (1) in figure $3 \mathrm{~b}$ is the desired course of knee joint load, while grey (2) one is mechanical axis of the knee joint.

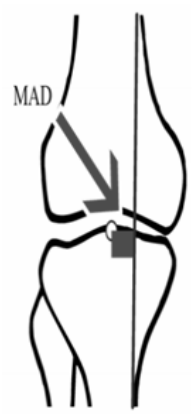

Fig. 4. Defining the direction and deviations of the mechanical axis [13]

Another method of deformation evaluation used in planning operations is the procedure developed by Paley [19]. It is used in cases where the deformation angle is high and in cases where the incorrect course of the mechanical axis of the knee joint results from deformation of the tibia or femur $[19,20]$. In the first step, the incorrect mechanical axis of the limb should be determined. The lines are plotted on the frontal plane when the patient stands with their patella to the front [19]. The tibial knuckles are taken as the reference point for the measurement [19]. The direction of mechanical axis deviation of the knee joint (MAD mechanical axis deviation) is then drawn. This allows the determination of the nature and value of the axle deviation. The direction of deformity speaks of varus deformity or valgus deformity of the knee joint. The determination of MAD is shown in figure 4. Normal value of MAD is 3 to $17 \mathrm{~mm}$ [19]. In the case of varus deformation, MAD is generated by the incompatibility of the joint and the deformation of the tibia or femur. In order to determine knee joint inaccuracy, the joint-line convergence angle (JLCA) is determined. Its value should be in the range of 0 to 3 degrees for the joint without deformation [19]. This angle is formed between the tangent line to the femoral condyles and the tangent line to the articular surfaces of the tibia, as shown in figure 5a. To determine the deformation of the femoral or tibial bone, the LDFA (lateral distal femoral angle) is determined for femoral distortion and MPTA (medial proximal tibial angle) for the tibia bone. The LDFA angle is between the mechanical axis of the femur and the mechanical axis of the knee joint, while the MPTA angle is between 
the mechanical axis of the tibia and the mechanical axis of the joint [19]. Both angles are shown in figure $5 b$.

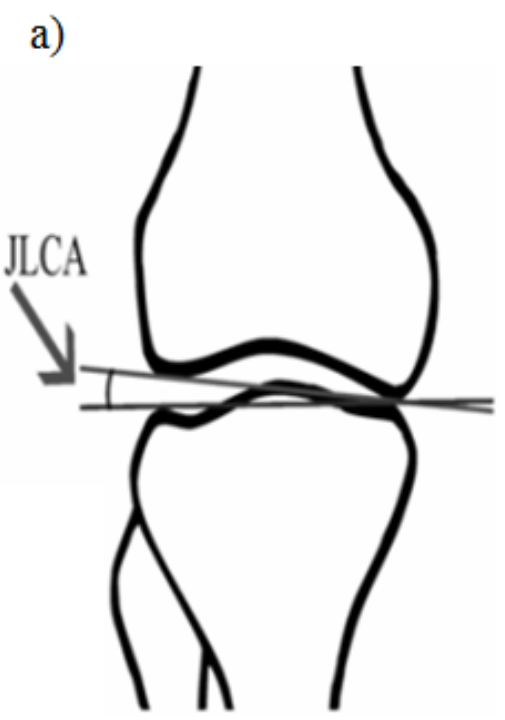

b)



Fig. 5. a) Defining the JLCA angle [1], b) LDFA and MPTA angles [19]

The normal value for the LDFA angle lies in the range of 88 to 95 degrees [19], and for the MPTA angle 86 to 89 degrees [19]. In the last step, the location of the centre of angular deformation CORA (centre of rotation of angulation) is determined. This is done by plotting the mechanical axis of the femur and the mechanical axis of the tibia derived from the centre of the upper ankle joint. The point of intersection of straight lines determines the position of CORA. The angle between them is the correction angle. It is shown in figure 6 .

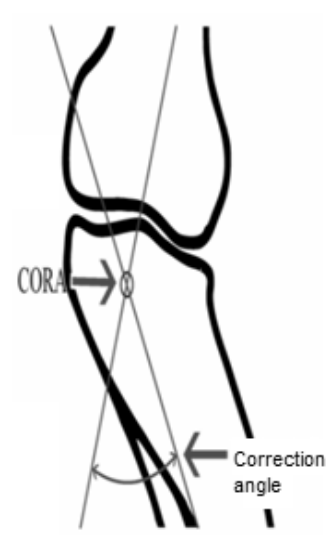

Fig. 6. CORA point and correction angle [13]

Complications that may occur after popliteal osteotomy are [21]:

- infection of the osteotomy gap,

- instability of the knee,

- stiffness of the knee,

- intra-articular fracture, 
- a recurrence of deformed joint deformity,

- a syndrome of fascia compartments,

- necrosis of the proximal part of the tibia,

- damage to the peroneal nerve,

- adverse change in the inclination angle of the articular surface of the tibia,

- insufficient pond correction,

- phlebitis of surface veins,

- parasthesia of the skin,

- fibular nerve dysfunctions,

- adhesion disorder.

Complications occur in 25 to $34 \%$ of the studied group [21]. The right choice of dimensions can significantly reduce the incidence of complications after surgery.

The above analysis allowed determining that none of the procedures takes into account differences in bone and steel stiffness. It is necessary to verify the effect of various bone and steel stiffness modules on the correction angle.

\section{METHOD AND EXPERIMENTS}

The images used to determine the dimensions of the bone wedge are taken when the limb is loaded by placing the patient in a standing position. This allows taking into account bone deformation from static loads generated by human mass. None of the methods of selecting the dimensions of the bone wedge takes into account differences in the mechanical properties of different materials. Deformation should be understood as the ratio of the change in the length of the object to its initial length, expressed as a percentage, described in the following formula:

$$
\varepsilon=\frac{\Delta l}{l}
$$

where: $\varepsilon$ - strain, $\Delta 1$ - elongation, 1 - initial length.

The elongation itself can be described by the formula:

$$
\Delta l=\frac{l \cdot F}{A \cdot E}
$$

where: $\mathrm{F}$ - force acting on the body, A - cross-sectional area, E - Young's modulus.

In turn, the stress in the general case is described by the formula:

$$
\sigma=E \cdot \varepsilon
$$

where: $\sigma-$ stress, E - Young's modulus, $\varepsilon$-deformation.

From the above formulas, it appears that the force acting on the bone and implant will be the same; the same applies to the cross-section. We treat cross section and force together for bone and implant, as shown in figure 7. One of the main mechanical properties is the Young's modulus. Young's modulus value in the human skeleton varies from 17 to $22 \mathrm{GPa}$ depending on the bone and the level of humidity [22]. In turn, Young's modulus for austenitic steels is about $200 \mathrm{GPa}$ [23]. The difference in module's values is about ten times. Theoretically, with the same loading condition, the side on which the implant is located will yield ten times less. 


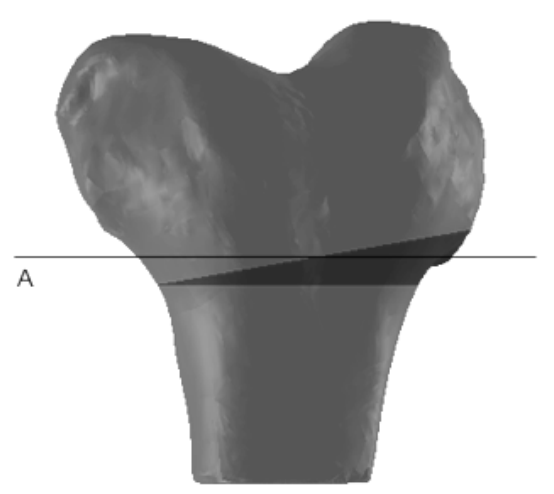

Fig. 7. Model of knee joint with opening wedge and marked cross-section A [24]

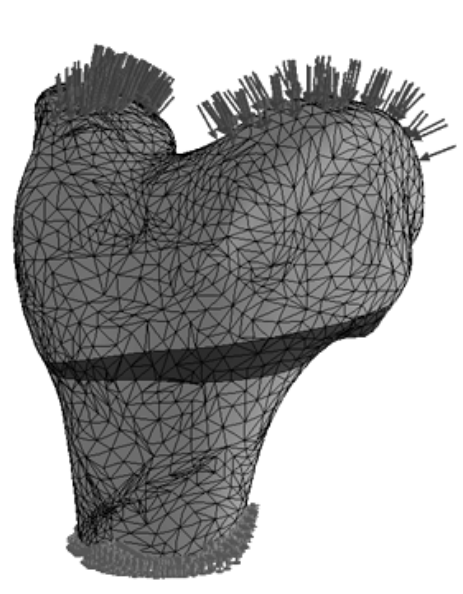

\begin{tabular}{|l|l|}
\hline $\begin{array}{l}\text { Study name } \\
\text { Mesh type }\end{array}$ & Static 1 (-Domyślna-) \\
\hline Mesher Used & Solid Mesh \\
\hline Automatic Transition & Standard mesh \\
\hline Include Mesh Auto Loops & 0 Off \\
\hline $\begin{array}{l}\text { Jacobian points } \\
\text { Element size }\end{array}$ & 4 points \\
\hline Tolerance & $5.32145 \mathrm{~mm}$ \\
\hline Mesh quality & $0.266072 \mathrm{~mm}$ \\
\hline Total nodes & High \\
\hline $\begin{array}{l}\text { Total elements } \\
\text { Maximum Aspect Ratio }\end{array}$ & 39478 \\
\hline $\begin{array}{l}\text { Percentage of elements } \\
\text { with Aspect Ratio }<3\end{array}$ & 26114 \\
\hline $\begin{array}{l}\text { Percentage of elements } \\
\text { with Aspect Ratio }>10\end{array}$ & 657.22 \\
\hline $\begin{array}{l}\text { \% of distorted elements } \\
\text { (Jacobian) }\end{array}$ & 90.4 \\
\hline Time to complete mesh(hh:mm:ss) & $00: 00: 47$ \\
\hline Computer name & MA:1041 \\
\hline
\end{tabular}

Fig. 8. Meshed model of the knee joint with restraint and load and parameters of the mesh model

To illustrate the phenomenon, a simplified analysis was carried out. The study was performed in the SolidWorks Simulation software. The analysis was carried out for a correction of $10^{\circ}$. The model presented in figure 7 has been transformed into a mesh model as shown in figure 8 . The model consisted of 26114 tetra elements with 4 integration points and an average element size of $5.32 \mathrm{~mm}$.

Boundary conditions are described below. The solid was fixed at the bottom, rotations and translations for all axes were removed. Contact between solid bodies has been defined as being bonded with a compatible mesh. This means nodes of both meshes along the contact surface are merged. A load equivalent to half of the normal man-weight mass of the human body, i.e. $392.4 \mathrm{~N}$, was applied to pond surfaces, assuming that the gravitational acceleration $g$ is $9.81 \mathrm{~m} / \mathrm{s}^{2}$. The bone consists of cortical tissue (external) and cancellous (internal) tissue. The mechanical properties of both are extremely different. Range of Young's modulus of cortical bone is 17 to $21 \mathrm{GPa}[25,26]$. Range of Young's modulus of cancellous bone is 350 $\mathrm{MPa}$ to $15 \mathrm{GPa}[25,26]$. In the analysis an elastic modulus equal to $18.4 \mathrm{GPa}$ and the fact that the whole bone is made of cortical tissue were adopted. In the first phase of the study, it was assumed that the wedge and bone materials are identical and have parameters characteristic of the moist tibia, elastic modulus equal to $18.4 \mathrm{GPa}$ and strength limits equal to $162 \mathrm{MPa}$ [22]. Next, the wedge was assigned to be made of material AISI $316 \mathrm{~L}$ acid-proof steel with 
Young's modulus equal to $193 \mathrm{GPa}$, strength limit equal to $550 \mathrm{MPa}$ and yield strength equal to $138 \mathrm{MPa}$.

\section{RESULTS AND DISCUSSION}

Below, in figures from 9 to 14, the results of the above analyses are presented.
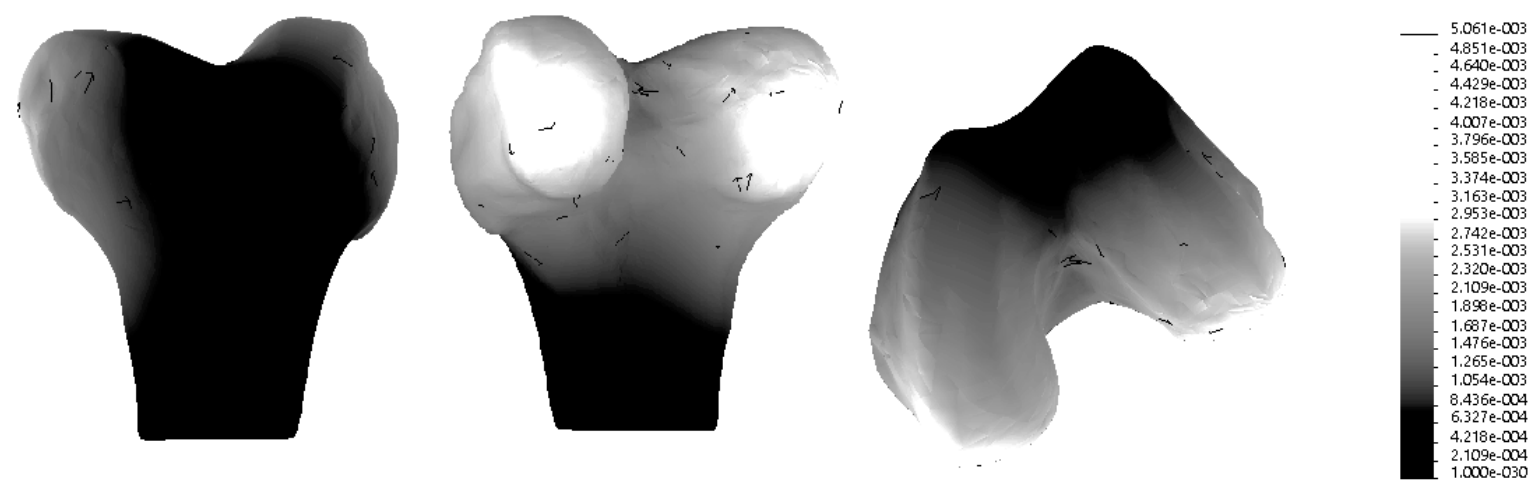

Fig. 9. Resultant deformation of the proximal tibial bone (both materials - bone)
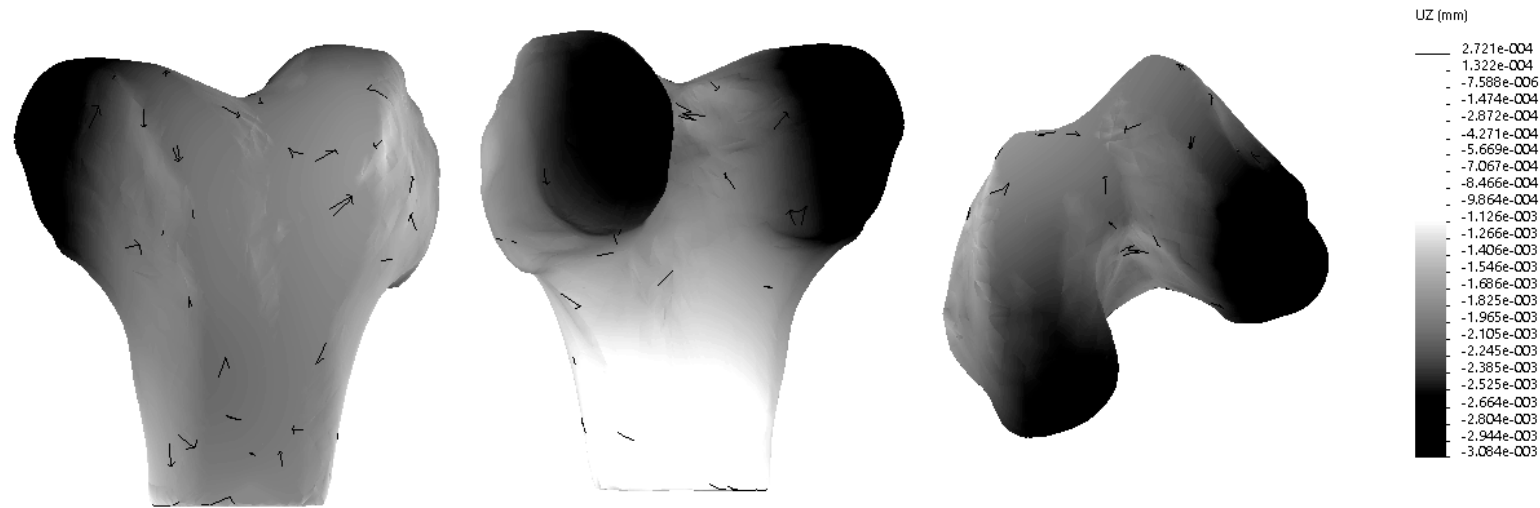

Fig. 10. Deformation of the proximal tibia along $Z$ axis (both materials - bone)
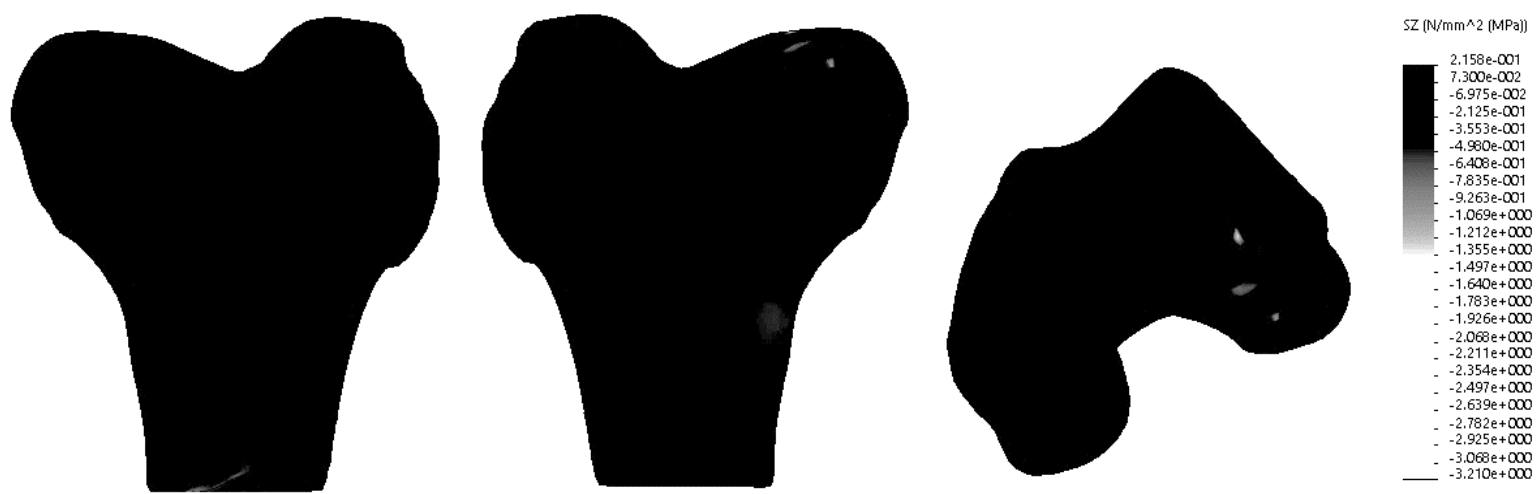

Fig. 11. Normal stresses along the $Z$ axis (mechanical knee axis) of the proximal tibia (both materials - bone) 
In the case of a uniform bone, the maximum displacement was $5.06 \cdot 10^{-3} \mathrm{~mm}$ and was located within the lateral tibial condyle. However, the difference in deflection between the medial and lateral condyles was $0.42 \cdot 10^{-3} \mathrm{~mm}$.
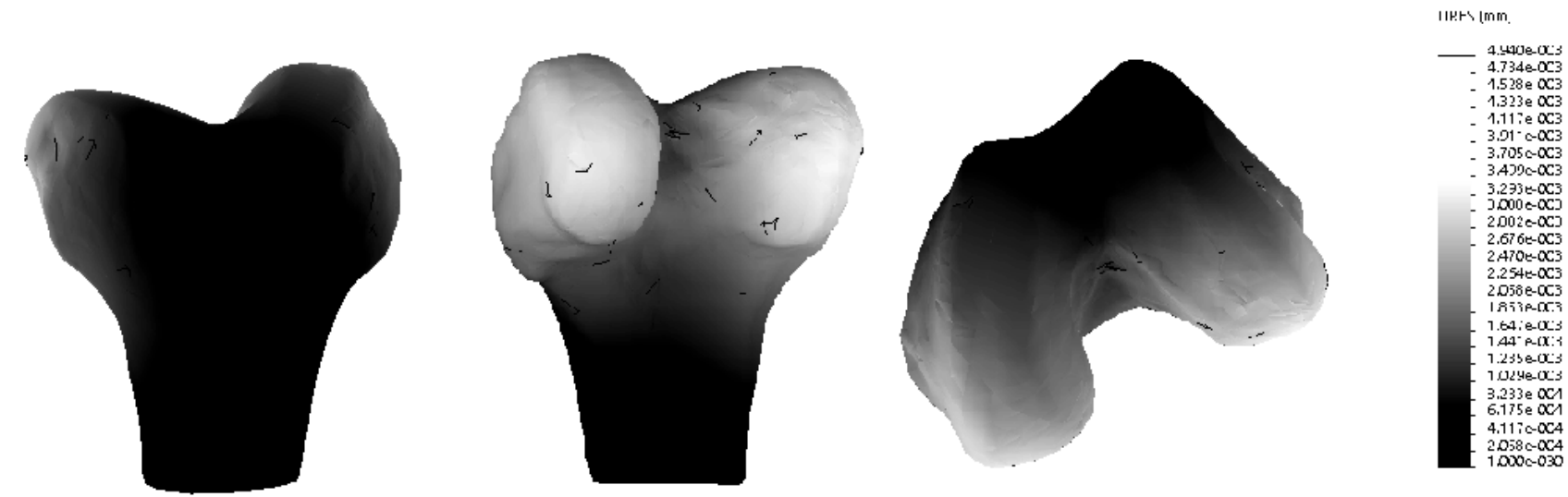

Fig. 12. Resultant deformation of the proximal tibial bone (wedge material - AISI 316L steel)
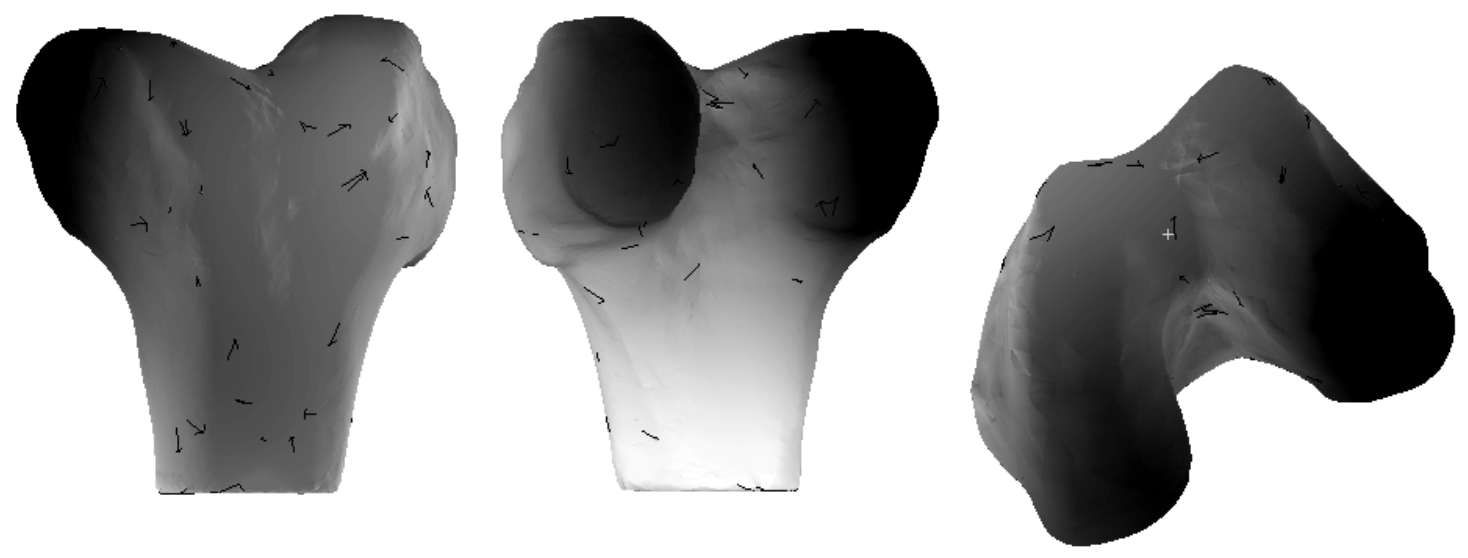

$\mathrm{UZ}(\mathrm{mm})$

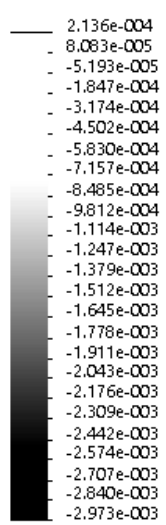

Fig. 13. Deformation of the proximal tibia along $Z$ axis (wedge material - AISI 316L steel)
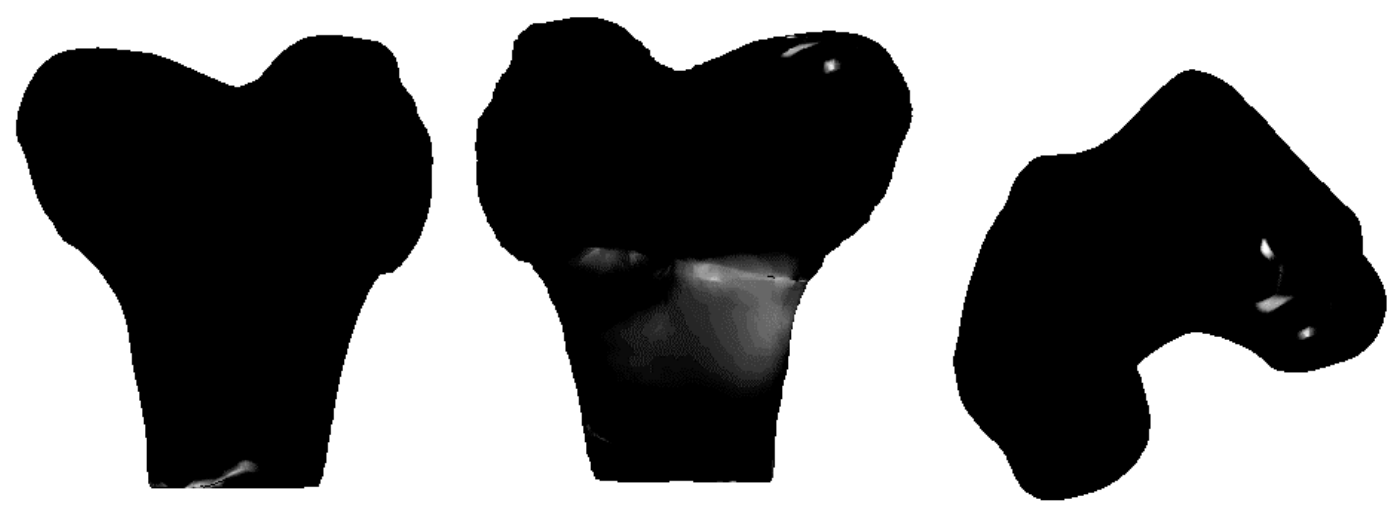

$\mathrm{Sz}\left(\mathrm{N} / \mathrm{mm}^{\wedge} 2(\mathrm{MPa})\right)$

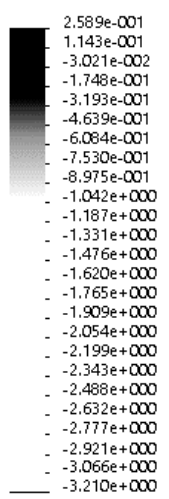

Fig. 14. Normal stresses along the $Z$ axis (mechanical knee axis) of the proximal tibia ( wedge material - AISI 316L steel) 
In the case of analysis performed for a wedge made of AISI 316L steel, the maximum deformations are smaller and amount to $4.94 \cdot 10^{-3} \mathrm{~mm}$. In turn, the difference in the deflection between the knuckle supported on the wedge and the lateral knuckle is $0.823 \cdot 10^{-3} \mathrm{~mm}$. In the stress distribution along $Z$ axis one can observe a clear manifestation of the stress jump at the material boundary. Stresses within the wedge amount from -1.477 to $0.2589 \mathrm{MPa}$, and in the bone surrounding the wedge, these values range from -0.753 to $-0.1748 \mathrm{MPa}$.

In the first study the difference in deformation of condyles is $0.422 \cdot 10^{-3} \mathrm{~mm}$, in the second one it is $0.823 \cdot 10^{-3} \mathrm{~mm}$. The difference in deformation of condyles is nearly twice as high in second as in the first one. Difference in deformation of steel wedge side and bone side is $0.823 \cdot 10^{-3} \mathrm{~mm}$. The HTO was planned for 10 degrees correction. The difference caused knee axis deviation by 0.0065 degrees from planed orientation.

\section{CONCLUSIONS}

Almost double difference in stresses shows that most of the load is transferred through the steel wedge and not through the bone on the lateral side of the knee joint. This means that the bone tissue may not be loaded enough to induce proper arrangement of bone bars. According to the Wolff-Delpech law, the squeezed bone disappears while the extended bone expands $[27,28]$. The microstructure of the bones is in continuous reconstruction, the bone bars are arranged in accordance with the course of the main anatomical axes [28]. In the case of uneven bone loading within the osteotomy, bone tissue may disappear. This may result in complications such as relapse or intra-articular fracture.

In the case studied, a correction of $10^{\circ}$ was adopted as one of the most common [29]. It should be noted that osteotomy implant manufacturers produce implants with up to $15^{\circ}$ [30], whereas treatments with higher correction angle magnitude are also performed. The obtained results of the deformation of the condyles indicate that the intended correction angle has not been obtained. The difference can cause complications after surgery.

The influence of Young's modulus on the correct result of the operation is visible. The results show that inclusion of Young's modulus in the selection of correction can eliminate some complications.

With the increase in the correction value, the difference in the deflection of the medial and lateral condylar of the knee joint will grow, and the nature and distribution of stresses in the wedge area and in the surrounding tissues will change. In addition, the knee joint is dynamically loaded at every step during walking and running and many activities performed in a vertical position, which was not included in the study. The reaction forces from dynamic forces are many times greater which results in an increase of strains and stresses in the joint. Dynamic states of knee joint load after osteotomy require in-depth analysis using appropriate tools.

\section{REFERENCES}

1. Franz A., Joseph L., Mayer C., Harmsen JF., Schrumpf H., Fröbel J., Ostapczuk MS., Krauspe R., Zilkens C., The role of oxidative and nitrosative stress in the pathology of osteoarthritis: Novel candidate biomarkers for quantification of degenerative changes in the knee joint. Orthopaedic Reviews 10:7460 (2018) 1-7. 
2. Allen K. D., Golightly Y. M., Epidemiology of osteoarthritis: state of the evidence. Current opinion in Rheumatology 27(3) (2015) 276-283.

3. Kumagai K., Akamatsu Y., Kobayashi H., Kusayama Y., Koshino T., Saito T., Factors affecting cartilage repair after medial opening-wedge high tibial osteotomy. Knee Surgery, Sports Traumatology, Arthroscopy 25(3) (2017) 779-784.

4. Saini M., Singh Y., Arora P., Arora V., Jain K., Implant biomaterials: A comprehensive review. World Journal of Clinical Cases 16; 3(1) (2015) 52-57.

5. Kongcharoensombat W., Clinical Outcome of Medial Opening Wedge Osteotomy with TLocking Plate: Two Years Follow-Up. Malaysian Orthopaedic Journal 8(1) (2014) 50-55.

6. Diffo Kaze A., Maas S., Waldmann D., Zilian A., Dueck K., Pape D., Biomechanical properties of five different currently used implants for open-wedge high tibial osteotomy. Journal of Experimental Orthopaedics 2:14 (2015) 1-17.

7. DePuy, Synthes Trauma, a division of Synthes GmbH.: For Medial High Tibial Osteotomies TomoFix ${ }^{\text {TM }}$ Medial High Tibial Plate (MHT). Oberdorf, 2017.

8. Koh Y-G., Son J., Kwang Kwona S., Jeong Kim H., Kang K-T., Biomechanical evaluation of opening-wedge high tibial osteotomy with composite materials using finite-element analysis. The Knee 25:6 (2018) 977-987.

9. Mahmoud D., Elbestawi M. A., Lattice Structures and Functionally Graded Materials Applications in Additive Manufacturing of Orthopaedic Implants: A Review. Journal of Manufacturing and Materials Processing 1(2) 13 (2017) 1-19.

10. Pal Singh A., Knee joint anatomy, (source: http://boneandspine.com/knee-joint-anatomy/ availability on 07.04.2018).

11. Gerster J.C., Landry M., Duvoisin B., Rappoport G., Computed tomography of the knee joint as an indicator of intraarticular tophi in gout. Arthritis \& Rheumatology 39(8):1406-9 (1996).

12. Hombach-Klonisch S., Klonisch T., Peeler J,. Sobotta Clinical Atlas of Human Anatomy, one volume, English. Urban \& Fischer (2019).

13. Sergiew M., Osteotomia rozwierająca piszczeli w leczeniu choroby zwyrodnieniowej stawu kolanowego, PhD thesis, Uniwersytet Medyczny im. Karola Marcinkowskiego w Poznaniu, Poznań 2010.

14. Lobenhoffer P., Agneskirchner J.D., Improvements in surgical technique of valgus high tibial osteotomy. Knee Surgery, Sports Traumatology Arthroscopy 11(3) (2003) 132-8.

15. Rao A., Erickson BJ., Cvetanovich GL., Yanke AB., Bach BR. Jr., Cole BJ., The MeniscusDeficient Knee: Biomechanics, Evaluation, and Treatment Options. The Orthopaedic Journal of Sports Medicine 3(10) (2015) 1-14.

16. Cavallo M., Sayyed-Hosseinian SH., Parma A., Buda R., Mosca M., Giannini S., Combination of High Tibial Osteotomy and Autologous Bone Marrow Derived Cell Implantation in Early Osteoarthritis of Knee: A Preliminary Study. The Archives of Bone and Joint Surgery 6(2) (2018) 112-118.

17. Canale S.T., Campbell's Operative Orthopaedics. Mosby; 9th edition,1999.

18. Hagstedt B., Norman O., Olsson T.H., Tjörnstrand B., Technical Accuracy in High Tibial Osteotomy for Gonarthrosis, Acta Orthopaedica Scandinavica, 51:1-6, (1980) 963-970.

19. Paley D., Herzenberg J.E., Tetsworth K., McKie J., Bhave A., Deformity planning for frontal and sagittal plane corrective osteotomies. Orthopaedic Clinics of North America 25(3) (1994) 425465. 
20. Paley D., Tetsworth K., Mechanical Axis Deviation of the Lower Limbs: Preoperative Planning of Uniapical Angular Deformities of the Tibia or Femur. Clinical Orthopaedics and Related Research 280(280) (1992) 65-71.

21. Seo S., Kim O-G., Seo J-H., Kim D-H., Kim Y-G., Lee I-S., Complications and Short-Term Outcomes of Medial Opening Wedge High Tibial Osteotomy Using a Locking Plate for Medial Osteoarthritis of the Knee. Knee Surgery \& Related Research 28(4) (2016) 289-296.

22. Pal S., Design of Artificial Human Joints \& Organs. Springer, 2014, 23-40.

23. Balijepalli S.K., Donnini R., Kaciulis S., Montanari R., Varone A., Young's Modulus Profile in Kolsterized AISI 316L Steel. Materials Science Forum 762:183 (2013).

24. Human knee joint model from CT scan data, (source: https://grabcad.com/library/human-knee-1 availability on 05.04 .2018 ).

25. Lai Y-S., Chen W-C., Huang C-H., Cheng C-K., Chan K-K., Chang T-K., The Effect of Graft Strength on Knee Laxity and Graft In-Situ Forces after Posterior Cruciate Ligament Reconstruction. PLoS ONE 10(5) (2015).

26. Rao J. Y. Ashman R.B., Turner C.H., Young's modulus of trabecular and cortical bone material: Ultrasonic and microtensile measurements. Journal of Biomechanics 26 (2) (1993), 111-119.

27. Teichtahl A., Wluka A., Wijethilake P., Wang Y., Ghasem-Zadeh A., Cicuttini F., Wolff's law in action: a mechanism for early knee osteoarthritis. Arthritis Research \& Therapy 17(1) (2015) 1-9.

28. Mirzaali M. J., Mussi V., Vena P., Libonati F., Vergani L., Strano M., Mimicking the loading adaptation of bone microstructure with aluminum foams. Materials \& Design 126 (15) (2017) 207-218.

29. Myrnerts R., Optimal Correction in High Tibial Osteotomy for Varus Deformity. Acta Orthopaedica Scandinavica, 51 (4) 1-6, (1980) 689-693.

30. Arthrex, iBalance ${ }^{\circledR}$ HTO System Surgical Technique. Naples, 2018. 